\title{
Cannabis Use for Therapeutic Purposes by Children and Youth at a Tertiary Teaching Hospital in Canada: A Retrospective Chart Review
}

\author{
Régis Vaillancourt, Maria Moreno, Annie Pouliot, and Erick Sell
}

\begin{abstract}
Background: The study of the use of cannabis for therapeutic purposes in the pediatric population is increasing, yet data on efficacy and safety are limited. Characterization of pediatric cannabis use for therapeutic purposes will improve understanding of the circumstances under which it occurs and the associated outcomes.

Objective: To describe the use of cannabis for therapeutic purposes, regardless of authorization, in a pediatric tertiary teaching hospital.

Methods: A retrospective chart review was completed for patients 18 years of age or younger who used cannabis for therapeutic purposes, regardless of authorization, between May 1, 2014, and May 1, 2017. Patients whose cannabis use was documented as recreational were excluded.

Results: In total, 300 patients were identified, of whom 37 met the inclusion criteria. Of these, 30 patients had documentation of medically supervised cannabis use. Most were using cannabis for seizures $(n=28)$, and many of these $(n=23)$ were patients with seizures described as intractable or refractory. Of the 27 patients who were experiencing seizures at initiation of medical cannabis, 21 had documentation of a decrease in seizure frequency. This decrease was transient for 16 patients, with a mean duration of 130.4 days (standard deviation 99.1 days). Seven patients self-medicated with cannabis. They obtained cannabis without authorization and used it for chronic pain $(n=5)$ and/or anxiety $(n=5)$.

Conclusions: Medically supervised cannabis use occurred most often in patients with intractable or refractory seizures. According to these data, seizure response is variable, and initial decreases may be transient for pediatric patients using cannabis. To ensure greater consistency and rigour in the conduct of prospective research and thus to generate better-quality research on the therapeutic effects of medical cannabis, development of a standardized care record is needed.
\end{abstract}

Keywords: cannabis, pediatrics, tertiary care, seizures, therapeutic

Can J Hosp Pharm. 2020;73(2):105-15

\section{RÉSUMÉ}

Contexte : Les études portant sur l'utilisation du cannabis à des fins thérapeutiques par les enfants augmentent, mais les données concernant l'efficacité et la sécurité de cette drogue sont limitées. La caractérisation de l'usage du cannabis à des fins thérapeutiques permettra de mieux comprendre les circonstances de l'utilisation de cette drogue ainsi que les effets qui lui sont associés.

Objectif : Décrire l'utilisation du cannabis à des fins thérapeutiques, qu'elle soit autorisée ou non, dans un hôpital d'enseignement de soins pédiatriques tertiaires.

Méthodes : Un examen rétrospectif des dossiers a été mené auprès de patients d'âge égal ou inférieur à 18 ans, qui ont fait un usage autorisé ou non de cannabis à des fins thérapeutiques entre le $1^{\text {er }}$ mai 2014 et le $1^{\text {er }}$ mai 2017. Les patients qui utilisaient du cannabis à des fins récréatives ont été exclus de l'étude.

Résultats : Au total 300 patients ont été identifiés et 37 d'entre eux répondaient au critère d'inclusion. La prise de cannabis sous supervision médicale de 30 d'entre eux était documentée. La plupart utilisaient le cannabis en cas de crise $(n=28)$ et bon nombre d'entre eux $(n=23)$ étaient des patients dont les crises étaient décrites comme insolubles ou réfractaires. Des 27 patients qui avaient des crises au début de la prise de cannabis médical, 21 ont enregistré une diminution de la fréquence des crises. Seize patients ont obtenu une diminution éphémère, qui a duré en moyenne 130,4 jours (écart type : 99,1 jours). Sept patients se soignaient eux-mêmes à l'aide de cannabis. Ils obtenaient du cannabis sans autorisation et l'utilisaient pour soulager des douleurs chroniques $(n=5)$ ou leur anxiété $(n=5)$.

Conclusions : Les patients qui subissaient des crises incurables ou réfractaires utilisaient le plus souvent du cannabis sous supervision médicale. Selon ces données, la réponse aux crises est variable et les baisses initiales du nombre de crises pourraient être éphémères chez les enfants utilisant du cannabis. Il convient de préparer un dossier de soins normalisé pour mener des recherches prospectives plus cohérentes et rigoureuses et donc générer des recherches de meilleure qualité sur les effets thérapeutiques du cannabis médical.

Mots-clés : cannabis, pédiatrie, soins tertiaires, crises, thérapeutique 


\section{INTRODUCTION}

Tn children, cannabis and pharmaceutical cannabinoids have Ibeen studied for multiple conditions, including refractory epileptic seizures, ${ }^{1-10}$ such as those associated with Dravet syndrome, Doose syndrome, Lennox-Gastaut syndrome, hypoxic damage, and idiopathic epilepsy; tics secondary to Tourette syndrome $^{11}$; neuropathic pain $^{12}$ and chronic pain from headaches ${ }^{13}$ and abdominal and musculoskeletal sources ${ }^{13}$; chemotherapy-induced nausea and vomiting ${ }^{14-18}$; spasticity $^{19}$; and post-traumatic stress disorder. ${ }^{20}$ In practice, cannabis has been used as a last-line therapy in pediatric cases where satisfactory improvement was not observed and conventional therapies were ineffective. ${ }^{6,10}$ Much of this evidence for the use of cannabis for therapeutic purposes in children comes from case reports and retrospective chart reviews, ${ }^{20}$ and stronger evidence is often lacking. ${ }^{20,21}$ Nonetheless, there is some good quality evidence, in the form of double-blind, crossover, randomized controlled trials, that pharmaceutical cannabinoids are effective in treating chemotherapy-induced nausea and vomiting in children. ${ }^{20}$ In addition, there have been several randomized, controlled, openlabel trials of a 99\% pure oral cannabidiol (CBD) extract that has been approved by the US Food and Drug Administration. ${ }^{22} \mathrm{~A}$ recent review of these trials indicated significant improvement in seizure frequency and severity in patients with medically refractory epilepsy. ${ }^{22}$

The outcomes used to evaluate the efficacy of cannabis therapy in children vary by indication, with the typical aim being a reduction in frequency or severity of symptoms (e.g., vomiting, seizure frequency, pain, or spasticity). ${ }^{20}$ In addition, some side effects of cannabis may be considered beneficial, such as improvement in sleep quality, increase in alertness, and improvement in mood, language, and motor skills. ${ }^{8}$ The most commonly reported side effects of tetrahydrocannabinol (THC) are drowsiness and dizziness,$^{20}$ whereas the most common side effects of CBD are somnolence, diarrhea, and decreased appetite. ${ }^{20}$ Other side effects include anxiety/agitation, ${ }^{23}$ fatigue, ${ }^{8,10,13}$ decrease in reflex responses, ${ }^{13}$ amotivation, ${ }^{13}$ hallucinations, ${ }^{23,24}$ emesis, ${ }^{23}$ increased appetite, ${ }^{6}$ tachycardia, ${ }^{6}$ and hypertension or hypotension (especially postural hypotension). ${ }^{24,25}$ As well, some patients using cannabis for seizure control experience a worsening of seizures. ${ }^{6,8}$ Some rare but serious adverse events may be linked to cannabis use and abuse, including atrial fibrillation, ${ }^{25,26}$ stroke, ${ }^{24,27}$ and status epilepticus in seizure-prone patients. ${ }^{8}$ Many adverse effects of long-term use of cannabis have been described, such as bronchitis, asthma, oropharyngitis, ${ }^{28}$ and impairment of school performance ${ }^{21}$ and social function. ${ }^{13}$ This group of side effects, however, is often related to intake of cannabis by smoking, which is not an accepted route of administration when cannabis is used for therapeutic purposes. ${ }^{21}$

The Canadian Paediatric Society states that there are currently insufficient data to support the efficacy and safety of cannabis for any therapeutic indication in children. ${ }^{21}$ Case reports discussing the successful use of cannabis to treat refractory epilepsy in children have spurred interest in using cannabis as pharmacotherapy for multiple indications. ${ }^{10,29}$ Conversely, a growing body of evidence has begun to delineate potential harms associated with cannabis use by adolescents, ${ }^{30}$ especially those with comorbid conditions, such as attention deficit hyperactivity disorder. ${ }^{31}$ The Canadian Paediatric Society has therefore provided recommendations for the therapeutic use of cannabis in exceptional pediatric cases, emphasizing the need for ongoing research to characterize its efficacy and safety. ${ }^{21}$

The objective of the current study was to describe, through a retrospective chart review, inpatient and outpatient use of cannabis for therapeutic purposes, regardless of authorization, at the Children's Hospital of Eastern Ontario (CHEO) over a 3-year period, from 2014 to 2017 . CHEO is a 167-bed pediatric tertiary teaching hospital in Ottawa, Ontario. CHEO has administered medical cannabis to patients in a number of exceptional circumstances, for multiple indications, with authorization from various health care practitioners. Given the lack of strong evidence for cannabis use for therapeutic purposes in children ${ }^{21}$ and the wide variety of indications, efficacy and safety outcomes, doses, dosage forms, and patient characteristics, the findings of this chart review will be useful to improve understanding of the circumstances under which cannabis is used for therapeutic purposes among children and youth in Canada and the associated outcomes.

\section{METHODS}

\section{Sample Selection}

In Canada, for the entire period of this chart review (20142017), it was permissible to obtain medical cannabis from a licensed producer or to grow it oneself with authorization (Table 1). ${ }^{32}$ The authorization for medical cannabis is obtained through a licensed health care professional, who provides suitable documentation to the patient; this documentation of authorization must then be presented to obtain medical cannabis from a licensed producer. Until 2016, medical cannabis was limited to dried marijuana ${ }^{32}$; however, changes to the regulations governing medical cannabis use in Canada that occurred partway through the study period (Table 1) included granting permission to those with authorization to buy cannabis oil and/or to make cannabis oil themselves.

For purposes of a study such as ours, confirmation of medical authorization for cannabis can be achieved either by verifying the source of cannabis to be a licensed producer or by verifying the medical authorization document. Given the retrospective nature of the study and the lack of standardization of documentation in patient charts, it was not possible to confirm medical authorization in each case. Therefore, we included all inpatients and outpatients 18 years of age or younger who were followed at $\mathrm{CHEO}$ between May 1, 2014, and May 1, 2017, and whose charts contained 


\begin{tabular}{|c|c|c|}
\hline Year & Regulation Name & Key Elements \\
\hline 2001 & Marihuana Medical Access Regulations & $\begin{array}{l}\text { - Allowed access to dried marijuana for medical purposes } \\
\text { with authorization from a health care practitioner } \\
\text { - Approved sources: } \\
\text { o Growing one's own plants } \\
\text { - Designating someone to grow plants } \\
\text { - Purchasing Health Canada supply }\end{array}$ \\
\hline$\overline{2013}$ & $\begin{array}{l}\text { Marihuana for Medical } \\
\text { Purposes Regulations }\end{array}$ & $\begin{array}{l}\text { - Expansion of approved sources of dried marijuana for } \\
\text { medical purposes to include licensed producers } \\
\text { - Created opportunity for development of a commercial } \\
\text { industry }\end{array}$ \\
\hline 2016 & $\begin{array}{l}\text { Access to Cannabis for Medical } \\
\text { Purposes Regulations }\end{array}$ & $\begin{array}{l}\text { - Allowed individuals with authorization for medical cannabis } \\
\text { to use and make cannabis products other than dried } \\
\text { marijuana, such as cannabis oil } \\
\text { - Allowed production and sale by licensed producers of fresh } \\
\text { and dried marijuana, cannabis oil, and marijuana seeds } \\
\text { and plants as starting materials } \\
\text { - Approved sources: } \\
\text { o Growing one's own plants } \\
\text { - Designating someone to grow plants } \\
\text { - Purchasing Health Canada supply }\end{array}$ \\
\hline
\end{tabular}

documentation of use of cannabis for therapeutic purposes, regardless of authorization.

Eligible patients were categorized as either using medical cannabis (i.e., using cannabis under medical supervision) or self-medicating with cannabis (see Box 1 for definitions of terms). Patients were considered to be using cannabis under medical supervision if any of the following criteria were met (as documented in the chart): a medical authorization document was verified; the source of the cannabis was verified as a licensed producer; or a physician was supervising the cannabis use, for example, by titrating the dose. Patients were considered to be self-medicating with cannabis if there was documentation that they were using cannabis for therapeutic purposes without medical supervision. Patients with documentation of self-medication with cannabis were included only if they also met all other inclusion criteria.

Patients were excluded if they were found, upon review of the medical record, to meet any of the following exclusion criteria: were using cannabis for therapeutic purposes, but with initiation outside the specified date range; were using cannabis for therapeutic purposes (e.g., anxiety, sleep), but with no further information documented; were using cannabis, but with documentation to indicate that use was recreational; were using a pharmaceutical cannabinoid only; or were not using cannabis.

\section{Procedure}

This retrospective chart review was approved by the Research Ethics Board of the Children's Hospital of Eastern Ontario Research Institute, which waived the requirement for informed consent.

The medical charts of inpatients and outpatients with documented use of cannabis for therapeutic purposes, regardless of authorization, were reviewed. Inpatients were identified by

\begin{tabular}{|l|}
\hline Box 1. Definitions of Key Terms for This Study \\
\hline Medically supervised use of cannabis: Cannabis was used under \\
medical supervision, regardless of whether medical authorization \\
was documented; does not include use of synthetic cannabinoids \\
\hline Self-medication with cannabis: Cannabis was used for therapeutic \\
purposes, but without medical supervision \\
\hline Pharmaceutical cannabinoids: Manufactured drugs, such as delta- \\
9-tetrahydrocannabinol-cannabidiol and nabilone, which have been \\
approved for specific indications by Health Canada
\end{tabular}

searching for cannabis in all medication orders logged in the hospital pharmacy's administrative software. Outpatients, for whom a different electronic health record was in use at the time, were identified in 2 ways. A search of medication orders and historical medications was performed for the medication numbers associated with the following 5 cannabis-related terms (or stems) in the outpatient electronic health record: cannabis, marijuana, cannabidiol/tetrahydrocann, cannabidiol-tetrahydrocannabin buccal, and cannabidiol-tetrahydrocannabinol $2.5-2.7 \mathrm{mg} /$ actuation buccal spray. Patients taking only pharmaceutical cannabinoids (e.g., the last of the medications in the list above) were excluded, but their charts were reviewed to identify any use of plant-based cannabis. In addition, to ensure a thorough search, a text-based search of the "Progress Notes" and "Medication Orders" sections of patients' chart was conducted for the words "cannabis", "marijuana", and "marihuana" for patients seen in clinics where medical cannabis was most likely to be used (i.e., chronic pain, gastroenterology, neurology, neurosurgery, and oncology). Electronic charts (for outpatients) and physical charts (for inpatients) were then reviewed in detail for relevant information. 


\section{Data Collection}

Data were extracted from the medical charts and entered into the Research Electronic Data Capture (REDCap) database (https://www.project-redcap.org/). Date of birth, sex, and allergies were collected. Information about the cannabis product, start date, dose, dosage changes, dosage form, route of administration, and end date (if applicable) was gathered, as well as information about use of tobacco and other substances. Any information about the indication, outcomes, side effects (adverse or beneficial), number of medications tried before cannabis, and nonpharmacological treatments used for the given indication were recorded. If cannabis had been discontinued, the reason was recorded. If cannabis had been used for a seizure disorder, the etiology of the disorder was recorded. For patients with documentation of a decrease in seizure frequency, the decrease was further classified as having been maintained or having been transient. To determine the duration of any observed decrease in seizure frequency, the number of days between initiation of cannabis and the first documented instance of increase in seizure frequency was calculated.

\section{RESULTS}

\section{Sample Characteristics}

Initial data capture identified a total of 300 unique patients whose medical charts were reviewed for eligibility. After review, 37 patients were included and 263 were excluded for the reasons specified in Figure 1. For most of those excluded $(n=128)$, review of the medical record showed that they were not using cannabis.
Patient characteristics for those included in the study are presented in Table 2, and the indications for use of cannabis in Table 3. Of the 37 patients included, 30 had documentation of medically supervised cannabis use (mean age at initiation 8.1 years, standard deviation [SD] 4.1 years), and 7 had documentation that they were self-medicating with cannabis (mean age at initiation 15.6 [SD 1.8] years). Of the 30 patients with medically supervised cannabis use, most were male $(n=23)$, the majority were being followed by the Neurology Clinic $(n=29)$, and most were using cannabis for seizures $(n=28)$. By contrast, among the 7 patients who were self-medicating with cannabis, most were female $(n=5)$, the majority were being followed by the Gastroenterology, Hepatology and Nutrition Clinic $(n=5)$ and/or the Chronic Pain Clinic ( $n=5)$, and most were using cannabis for chronic pain $(n=5)$ and/or anxiety $(n=5)$.

\section{Medically Supervised Cannabis Use}

For most patients, medically supervised cannabis use began after 2015 (Table 2). Slightly more than half were seen only as outpatients $(n=17)$. For half of these patients $(n=15)$, the source of cannabis was not documented in the patient chart. Fourteen patients obtained their cannabis from a licensed producer (Table 4). All 30 patients with medically supervised cannabis use had used an oil. For some of these patients, the oil was additional to other forms of cannabis. Of those using cannabis under medical supervision, 27 took it orally. Fourteen patients discontinued use during the period of the chart review. The most common reason for discontinuation was an increase in seizure frequency $(n=5$;

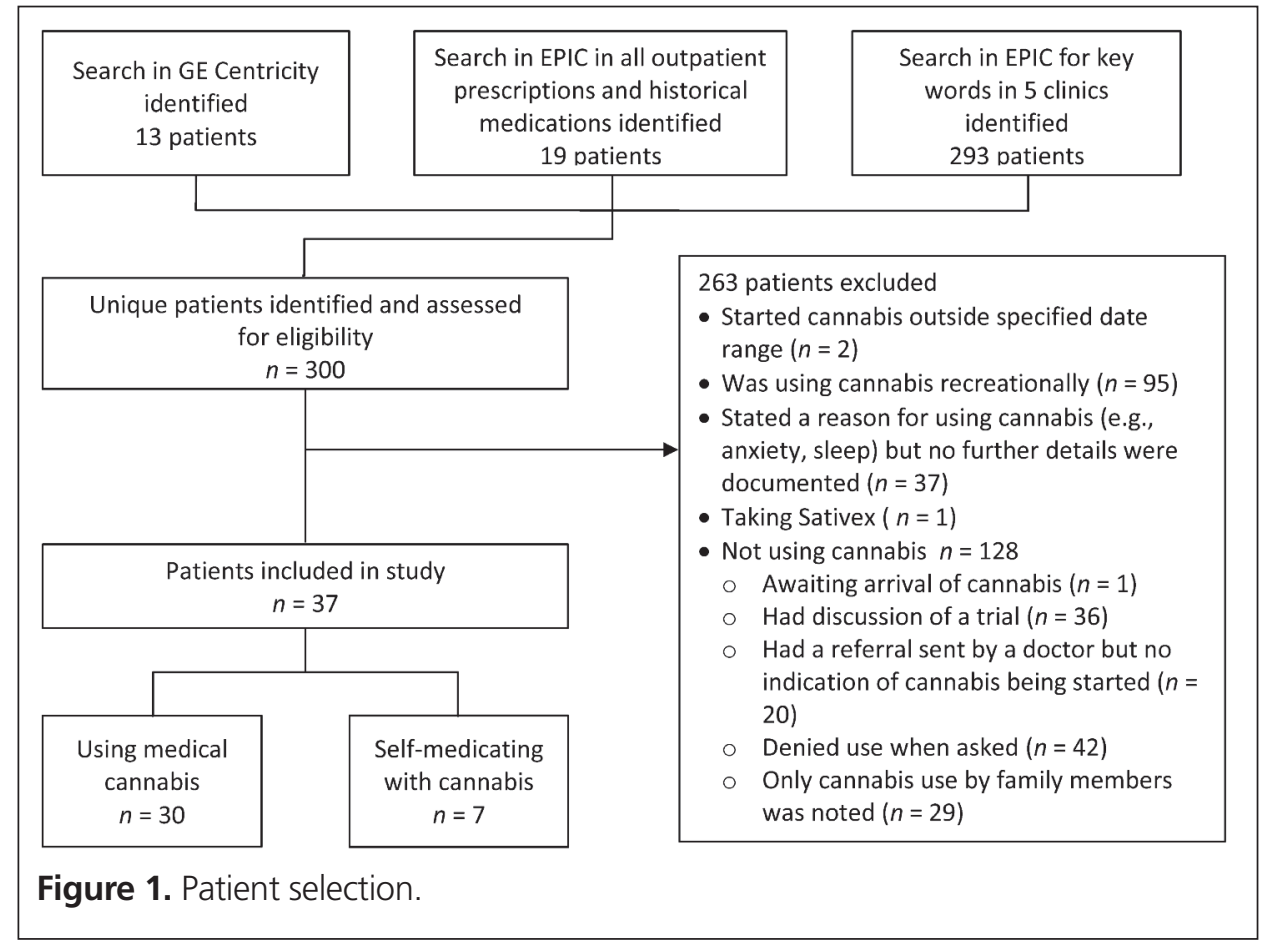


Table 2. Characteristics of Patients Included in the Study*

\begin{tabular}{|c|c|c|}
\hline Characteristic & $\begin{array}{l}\text { Medical Cannabis } \\
\quad(n=30)\end{array}$ & $\begin{array}{c}\text { Self-Medication } \\
\text { with Cannabis } \\
\quad(n=7)\end{array}$ \\
\hline Age at initiation of cannabis (years) (mean \pm SD) & $8.1 \pm 4.1$ & $15.6 \pm 1.8$ \\
\hline \multicolumn{3}{|l|}{ Sex } \\
\hline Male & 23 & 2 \\
\hline Female & 7 & 5 \\
\hline \multicolumn{3}{|l|}{ Year when patient began cannabis uset } \\
\hline 2013 & 1 & - \\
\hline 2014 & 4 & - \\
\hline 2015 & 9 & - \\
\hline 2016 & 10 & - \\
\hline 2017 & 6 & - \\
\hline \multicolumn{3}{|l|}{ Patient type } \\
\hline Both inpatient and outpatient & 11 & 0 \\
\hline Inpatient & 13 & 0 \\
\hline Outpatient & 28 & 7 \\
\hline \multicolumn{3}{|l|}{ Substance use } \\
\hline Tobacco & 0 & 2 \\
\hline Other substances & 0 & 4 \\
\hline \multicolumn{3}{|l|}{ Services following patient‡ } \\
\hline Neurology & 29 & 0 \\
\hline Complex care & 6 & 0 \\
\hline Palliative care & 6 & 0 \\
\hline Gastroenterology, hepatology, nutrition & 4 & 5 \\
\hline Endocrinology & 5 & 0 \\
\hline Autism program & 2 & 0 \\
\hline Ear, nose, and throat & 2 & 0 \\
\hline Nephrology & 2 & 0 \\
\hline Mental health & 1 & 4 \\
\hline Cardiology & 1 & 0 \\
\hline Urology & 1 & 1 \\
\hline Oncology & 1 & 0 \\
\hline Chronic pain & 0 & 5 \\
\hline Adolescent health & 0 & 2 \\
\hline ADHD/behavioural & 0 & 1 \\
\hline Outpatient observation period (days) (mean \pm SD) & $1443.5 \pm 593.4$ & $753 \pm 432.9$ \\
\hline \multicolumn{3}{|c|}{$\begin{array}{l}\text { ADHD = attention deficit hyperactivity disorder, SD = standard deviation. } \\
\text { * Data are presented as number of patients, except where indicated otherwise. } \\
\text { †For patients who were self-medicating with cannabis, data concerning start date were not available } \\
\text { (indicated by dashes). } \\
\text { fEach patient could be followed by more than one service. }\end{array}$} \\
\hline
\end{tabular}

Table 4). Among cases for which the ratio of CBD to THC was recorded $(n=17)$, more than half reported using more than one unique formulation. Whereas 8 of these patients $(47 \%)$ reported using a single formulation, 6 patients $(35 \%)$ reported the use of 2 formulations, 2 patients (12\%) reported the use of 3 formulations, and 1 patient $(6 \%)$ reported the use of 5 different formulations.

\section{Symptom Control}

The presence of symptom control was based on a physician's documentation indicating that the patients' symptoms were controlled. According to this definition, only 5 patients with medically supervised cannabis use achieved control over their symptoms during the observation period (Table 5). Among those who were using cannabis for seizure control and who were experiencing seizures at initiation of medical cannabis $(n=27)$, 21 had documentation of an initial decrease in seizure frequency (although this decrease was not characterized as "seizure control" in the patients' charts). Most of these patients $(n=16)$ experienced a transient decrease in seizure frequency, with the decrease lasting, on average, 130.4 (SD 99.1) days. The average number of antiepileptic medications taken concurrently with cannabis was 3.7 (SD 1.9), with a range from 0 to 8 . For patients with seizures described as refractory, the average number of antiepileptic medications taken concurrently with cannabis was 4.1 (SD 1.8), with a range from 1 to 8 .

\section{Side Effects}

For the 30 patients using medically supervised cannabis, the most commonly documented negative side effects were worsening of seizures ( $n=19)$, onset of a new type of seizure $(n=7)$, drooling $(n=6)$, and fatigue $(n=6)$ (Figure 2). The most commonly documented positive side effects were being more engaged $(n=5)$, 
Table 3. Indications for Which Cannabis Use Was Documented*

\begin{tabular}{|c|c|c|}
\hline Indication & $\begin{array}{l}\text { Medical Cannabis } \\
\qquad(n=30)\end{array}$ & $\begin{array}{l}\text { Self-Medication } \\
\text { with Cannabist } \\
\qquad(n=7)\end{array}$ \\
\hline Seizures & 28 & 0 \\
\hline \multicolumn{3}{|l|}{ Type of seizure } \\
\hline Dravet syndrome & 7 & \\
\hline Idiopathic & 5 & \\
\hline Hypoxic damage & 4 & \\
\hline Lennox-Gastaut syndrome & 2 & \\
\hline $\begin{array}{l}\text { Infantile spasms that progressed with new } \\
\text { seizure types }\end{array}$ & 2 & \\
\hline Febrile infection-related epilepsy syndrome (FIRES) & 2 & \\
\hline Other & 6 & \\
\hline Documentation that ketogenic diet was tried & 18 & \\
\hline Seizures described as intractable/refractory & 23 & \\
\hline $\begin{array}{l}\text { No. of medications tried by patients described } \\
\text { as having intractable/refractory seizures } \\
\text { (mean } \pm \text { SD, range) }\end{array}$ & $\begin{array}{l}7.1 \pm 2.7 \\
3-16\end{array}$ & \\
\hline No. of medications tried for seizures before & $6.4 \pm 2.9$ & \\
\hline cannabis (mean \pm SD, range) & $2-16$ & \\
\hline Spasticity or dystonia & 2 & 0 \\
\hline No. of medications tried before cannabis & 3 & \\
\hline Chronic pain & 0 & 5 \\
\hline Abdominal pain & & 2 \\
\hline Myofascial pain syndrome & & 2 \\
\hline Other & & 1 \\
\hline Anxiety & 0 & 5 \\
\hline For sleep & 0 & 2 \\
\hline Nausea & 0 & 1 \\
\hline
\end{tabular}

improved $\operatorname{mood} /$ feeling brighter $(n=5)$, increased alertness $(n=5)$, and improved motor skills $(n=4)$ (Figure 3$)$.

\section{Self-Medication with Cannabis}

For the 7 patients who were self-medicating, all obtained cannabis without authorization as a dried flower, and most $(n=6)$ inhaled the product by smoking (Table 4$)$. For all of these patients, there was a failure to achieve symptom control (Table 5). Among these patients, the most common negative side effects were emesis $(n=6)$, decreased appetite $(n=2)$, constipation $(n=2)$, and sleeping difficulties $(n=2)$. The positive side effects noted in this group were increased appetite $(n=2)$ and improved sleep quality $(n=1)$.

\section{DISCUSSION}

\section{Medically Supervised Cannabis Use}

Over the 3-year period of the chart review, there were 30 patients with documentation of medically supervised cannabis use. The majority were using cannabis for seizures, which were most often described in the chart as intractable or refractory. This finding is consistent with the recent and rapid increase in research studies investigating the use of medical cannabis in the treatment of epilepsy. ${ }^{20}$ Most patients in this study were male, and many were followed by the neurology, complex care, and palliative care services at CHEO. No use of tobacco or other substances was noted among patients using cannabis under medical supervision. None of the patients were using medical cannabis for control of chemotherapy-induced nausea and vomiting. This is not surprising, because although there is strong evidence for the use of synthetic cannabinoids in the treatment of chemotherapyinduced nausea and vomiting, evidence for plant-based cannabis in this context is lacking. ${ }^{20}$

All of the patients with medically supervised cannabis use were using an oil. We observed that details of this form of medical cannabis usage were not documented consistently for outpatients. It was frequently unclear whether the oil was purchased as a premade product or if the patient's parents had purchased cannabis as a dried flower and prepared the oil at home. Other details, such as the source of the cannabis, were not documented for half of the patients. Such documentation is an important aspect of verifying authorization. Furthermore, for many patients, the ratio of CBD to THC was not documented. For those who did have documentation of this ratio, the range was relatively wide, from as high as 50:1 to as low as 1:1.

Of the 28 patients who were using medical cannabis for seizure control, 27 had active seizures at the time of initiation, and 21 of these had documentation of decreased seizure frequency after initiation of cannabis. Porter and Jacobson ${ }^{10}$ completed a 
Table 4. Description of Cannabis Use*

\begin{tabular}{|c|c|c|}
\hline Cannabis-Related Information & $\begin{array}{l}\text { Medical Cannabist } \\
\quad(n=30)\end{array}$ & $\begin{array}{l}\text { Self-Medication } \\
\text { with Cannabist } \\
\qquad(n=7)\end{array}$ \\
\hline \multicolumn{3}{|l|}{ Source of cannabis } \\
\hline Canadian licensed producer & 14 & 0 \\
\hline Clinical trial & 1 & 0 \\
\hline Unauthorized acquisition & 0 & 7 \\
\hline Not documented & 15 & 0 \\
\hline \multicolumn{3}{|l|}{ Dosage form } \\
\hline Oil & 30 & 0 \\
\hline Purchased as oil & 16 & \\
\hline Purchased as dried flower and made into oil & 5 & \\
\hline Not specified & 9 & \\
\hline Capsules & 1 & 0 \\
\hline Powder & 1 & 0 \\
\hline Dried flower & 0 & 7 \\
\hline Dried flower in cookies & 1 & 0 \\
\hline \multicolumn{3}{|l|}{ Route of administration } \\
\hline Oral & 27 & 0 \\
\hline Gastrostomy tube or nasojejunal tube & 3 & 0 \\
\hline Inhaled, vaporization & 0 & 2 \\
\hline Inhaled, smoking & 0 & 6 \\
\hline Concerns expressed over cost of cannabis & 6 & 2 \\
\hline No. of doses documented per patient (mean \pm SD) & $5.4 \pm 4.6$ & $4.5 \pm 3.8$ \\
\hline Patients who discontinued cannabis & 14 & 1 \\
\hline Increase in seizures & 5 & 0 \\
\hline Not seeing a benefit & 4 & 1 \\
\hline Death & 2 & 0 \\
\hline No longer having seizures & 1 & 0 \\
\hline Cost & 1 & 0 \\
\hline Learning difficulties & 1 & 0 \\
\hline Behavioural problems & 1 & 0 \\
\hline EEG worsening & 1 & 0 \\
\hline Emesis & 1 & 0 \\
\hline
\end{tabular}

survey of parents whose children were using cannabidiol-enriched cannabis for epilepsy. Parents of 19 patients completed the survey, with $84 \%$ reporting decreases in seizure frequency. ${ }^{10}$ The range of CBD-THC ratios in that study was similar to what was found in the current study. A recent open-label trial of high-ratio therapy (50:1) for Dravet syndrome produced reductions in seizure frequencies for $79 \%$ of patients with daily doses ranging from 7 to $16 \mathrm{mg} / \mathrm{kg}$ of CBD and 0.14 to $0.32 \mathrm{mg} / \mathrm{kg}$ of THC. ${ }^{33} \mathrm{In}$ our chart review, only 1 patient for whom information on formulation was available was using a cannabis oil formulation with a CBDTHC ratio as high as 50:1, yet the percentage of patients reporting seizure reductions was similar.

Different formulations and concentrations will likely affect outcomes in terms of both efficacy and side effects. In the current chart review, roughly half of the patients for whom we had information on formulation used more than one formulation during the period of the chart review. It is unclear what effect switching between cannabis products with different concentrations of CBD and THC might have on seizure control. Although approximately three-quarters of the patients in the current study experienced a decrease in seizure frequency, the magnitude of the decrease was unclear because there was no standardized method of documenting seizure control in patient charts. For a small number of patients with documentation of a decrease in seizure frequency, the decrease was maintained over the chart review period $(n=5)$, but it is possible that the decrease in frequency did not continue beyond the review period. For the remaining 16 patients, the frequency of seizures was documented to have decreased initially with a later return to baseline or increase above baseline. For 5 of these patients with a transient decrease in seizure frequency, the parents opted to withdraw and then reinitiate cannabis. For 3 of these 5 patients, a second transient decrease in seizure frequency was noted.

These results provide insight into the course of symptoms in seizure disorders among patients with medically supervised cannabis use. Maa and Figi ${ }^{29}$ documented cases of children using cannabis who had a persistent decrease in seizures over 20 months and were able to wean off their antiepileptic drugs. Given this finding, some parents may be hopeful that an initial decrease in seizure frequency will be maintained. On the basis of our 
Table 5. Relation between Cannabis Use and Symptom Control

\begin{tabular}{|c|c|c|}
\hline Efficacy & $\begin{array}{l}\text { Medical Cannabis } \\
\qquad(n=29)^{*}\end{array}$ & $\begin{array}{c}\text { Self-Medication } \\
\text { with Cannabis } \\
\quad(n=7)\end{array}$ \\
\hline \multicolumn{3}{|l|}{ 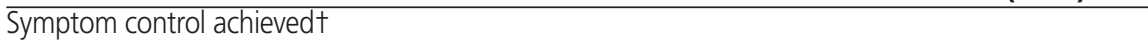 } \\
\hline Yes & 5 & 0 \\
\hline No & 24 & 7 \\
\hline \multicolumn{3}{|l|}{$\begin{array}{l}\text { Initial decrease in seizures }(n=27 \text { patients with seizures } \\
\text { upon initiation of cannabis)* }\end{array}$} \\
\hline Yes & 21 & NA \\
\hline No & 6 & NA \\
\hline Patients with decrease in seizures & $n=21$ & \\
\hline $\begin{array}{l}\text { Decrease in seizure frequency was maintained } \\
\text { Duration of decrease (days) (mean } \pm S D \text { ) }\end{array}$ & $\begin{aligned} n & =5 \\
267.0 & \pm 301.7\end{aligned}$ & \\
\hline \multicolumn{3}{|l|}{ Decrease in seizure frequency was transient } \\
\hline First attempt using cannabis & $n=16$ & \\
\hline Duration of decrease (days) (mean \pm SD) & $130.4 \pm 99.1$ & \\
\hline Second attempt using cannabis after stopping $(n=5)$ & $n=3$ & \\
\hline Duration of decrease (days) (mean \pm SD) & $150.3 \pm 44.1$ & \\
\hline Third attempt using cannabis after stopping $(n=1)$ & $n=1$ & \\
\hline Duration of decrease (days) & 39 & \\
\hline \multicolumn{3}{|c|}{$\begin{array}{l}\text { NA = not applicable, SD = standard deviation. } \\
\text { *Overall sample size was } 29 \text { patients using medical cannabis, with } 27 \text { of these patients using } \\
\text { medical cannabis for seizures (instead of } 30 \text { and } 28 \text {, respectively), because } 1 \text { of the } 28 \text { patients } \\
\text { using medical cannabis for seizures had not actually had any seizures for several months before } \\
\text { initiation of cannabis, and symptom/seizure control was therefore not a relevant outcome measure. } \\
\text { tSymptom control was defined as presence of physician documentation that symptoms were } \\
\text { controlled while patient was using cannabis. }\end{array}$} \\
\hline
\end{tabular}

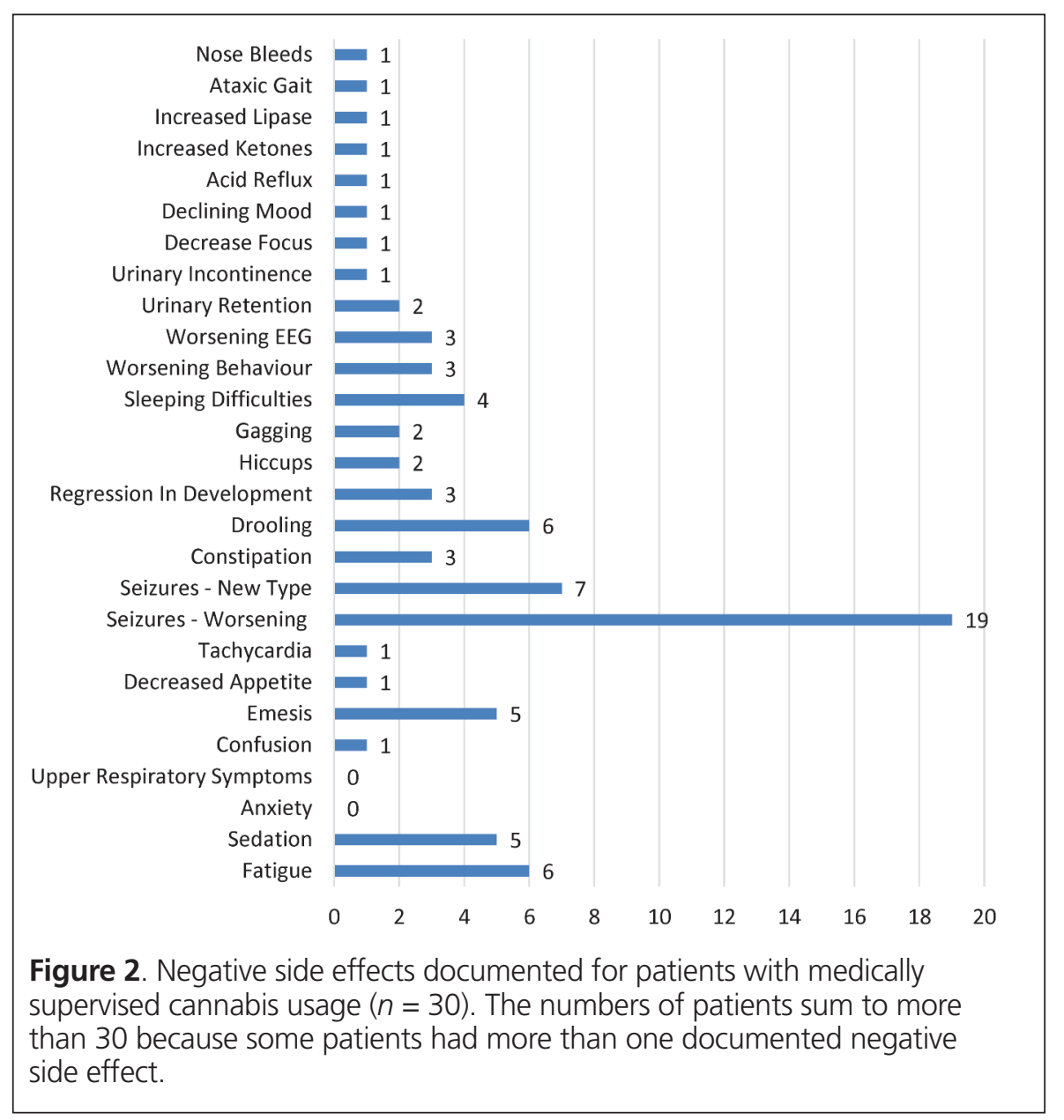




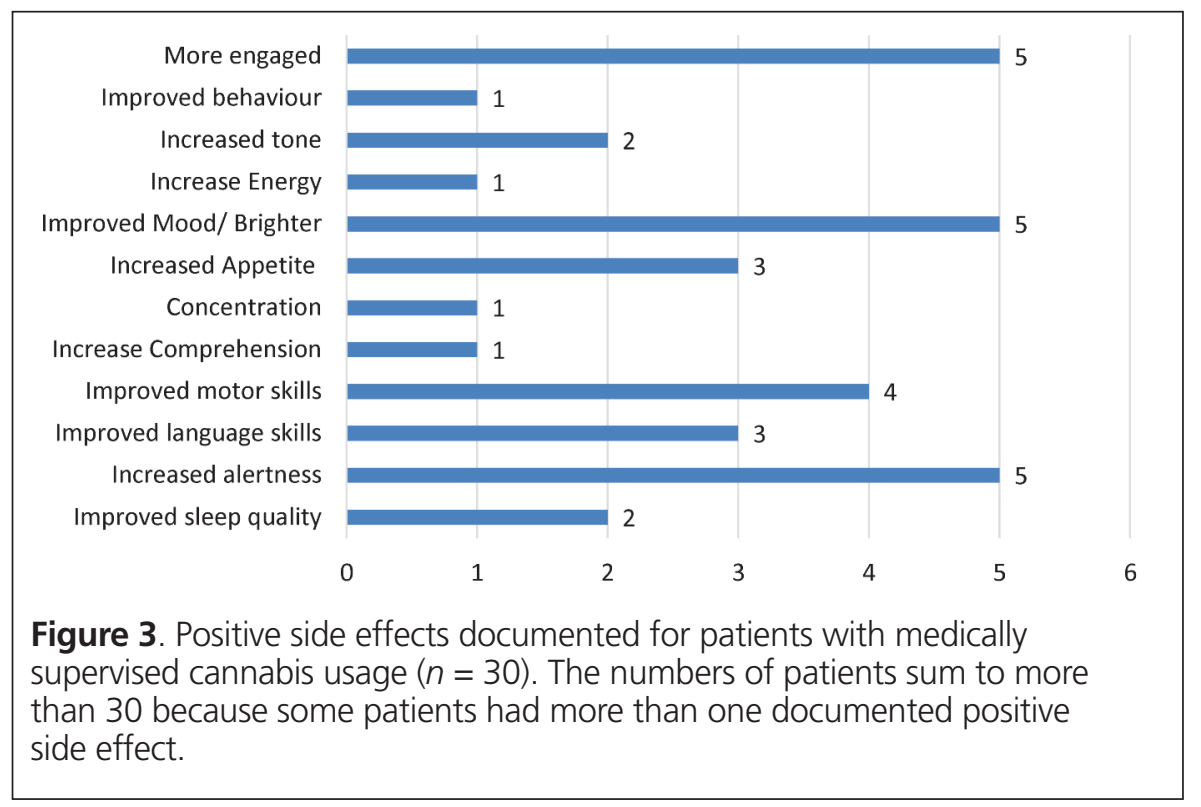

observations, we recommend that parents should be informed of the possibility that cannabis use may not be associated with long-term seizure control. Furthermore, an alternative (and counterintuitive) explanation for any observed decrease in seizure frequency may be weaning off existing antiepileptic drugs, as there have been instances where polypharmacy has worsened seizures. ${ }^{34}$

The most frequent negative side effect noted in the current study was worsening of seizures. Notably, 5 patients discontinued cannabis because of an increase in seizure frequency. This observation is consistent with previous reports of worsening of seizures associated with use of cannabis. ${ }^{6,8}$ The percentage of patients experiencing an increase in seizure frequency following medically supervised cannabis use was higher in the current study than that observed by Tzadok and others, ${ }^{6}$ who reported seizure aggravation for $7 \%$ of patients. The rate may have been higher in the current study because many patients experienced concurrent changes to their antiepileptic medications.

Positive side effects were also noted, such as improved alertness, improved or brighter mood, and being more engaged. These positive side effects can also be important to parents and may factor into the decision to continue medically supervised cannabis use, even if long-term symptom control is not achieved. Again, these positive side effects could be due to concurrently weaning off antiepileptic medications. ${ }^{35}$

\section{Self-Medication with Cannabis}

In this study, there were 7 outpatients who were selfmedicating with cannabis obtained from unauthorized sources. The average age in this group was 15.6 years, and most of the patients were female. The majority reported using cannabis for a chronic pain condition and/or anxiety. These findings are consistent with a recent survey by the Canadian Centre on
Substance Abuse, ${ }^{36}$ in which adolescents reported doing their own research and "self-medicating" with cannabis without consulting a doctor. Similar cases of adolescents using cannabis for pain were described by Harrison and others, ${ }^{13}$ who noted that full pain control was not achieved with cannabis use. Similarly, none of the patients in our study who were self-medicating with cannabis achieved control of their symptoms. Although some parents expressed concern about their children's use of cannabis, others had accepted it and allowed them to use it regularly. As explained by Harrison and others, ${ }^{13}$ parents may allow the use of cannabis when their child's symptoms are not well controlled by other means.

The Lower-Risk Cannabis Use Guidelines, developed by the Canadian Research Initiative in Substance Misuse, explain that smoking cannabis can have negative effects on respiratory health. ${ }^{37}$ The adolescents in our study were mostly smoking cannabis. Other side effects, such as emesis, can occur when cannabis is smoked. In the group of patients who smoked cannabis, there was some concurrent tobacco and substance use. This finding is consistent with information in the Canadian Paediatric Society position statement, ${ }^{38}$ which states that use of cannabis can lead to use of tobacco and other substances. As mentioned in that position statement, health care professionals should screen for cannabis use and discuss the risks of using cannabis regularly. ${ }^{38}$ Even if a child uses cannabis through self-medication, these discussions should still take place. The Lower-Risk Cannabis Use Guidelines also recommend abstinence and avoidance of initiation of cannabis at a young age, ${ }^{37}$ guidance that should be communicated to parents.

\section{Limitations}

This study was a retrospective chart review, and we acknowledge that the data collected are limited to the documentation 
available in the patients' medical records. For example, we were not able to describe the specific weight-based dosage of CBD (as milligrams per kilogram), which would be useful for understanding observed outcomes of CBD use in pediatric practice. In addition, we were unable to extract detailed information about the onset of efficacy. Furthermore, a relatively large number of patients $(n=37)$ had documentation of cannabis use for therapeutic purposes, but the information available was insufficient to characterize this use, and these patients were excluded. Therefore, the results of this study may not be generalizable to all pediatric patients who are using cannabis for therapeutic purposes. Cannabis was often authorized by physicians outside of CHEO, and information concerning authorization could only be obtained if it was well documented in the chart. There may have been instances in which a patient was using cannabis, but it was not documented or there was lack of detail because a CHEO physician was not the authorizing health care provider. Furthermore, the families of some outpatients may not have disclosed use of cannabis during their clinic visit for fear of stigma. Another limitation was our inability to objectively quantify seizure frequency because information for the study was limited to documentation in the patient chart, which was in turn based on parental characterization of seizure frequency. As such, these outcomes were limited by parental report and any bias that might have entailed.

\section{Implications}

According to the results of this study, we propose improving documentation of cannabis use for therapeutic purposes by integrating a template for documentation into the electronic medical record. Such a template would allow for more structured and standardized documentation of cannabis use. It could also facilitate future studies on the use of cannabis for therapeutic purposes. We propose that the elements required to effectively document the use of cannabis for therapeutic purposes, and thus improve understanding of its use in the pediatric population, are the following: start date; confirmation of authorization for cannabis, including name of the authorizing health care practitioner and expiry date of the certificate; brand name and source of cannabis (e.g.,. licensed producer); CBD-THC ratio; concentration of CBD for oils (e.g., as milligrams per millilitre $[\mathrm{mg} / \mathrm{mL}])$; route of administration; dose; and frequency of administration.

This information could be gathered by referring to both the medical document of authorization and the label of the product. In all cases of medical use of cannabis, a document provided by a health care practitioner is required to access the product. ${ }^{39}$ This document contains the authorizing practitioner's information and the period of use authorized. The labelling requirements for medical cannabis specify that the name of the licensed producer should be displayed along with the brand name. The THC and CBD content must also appear on the label for both oil and fresh/dried cannabis, and the label for any oil product must show the concentration. ${ }^{39}$

\section{CONCLUSION}

In this single-institution retrospective chart review, medically supervised cannabis use was documented most frequently for children with seizures described as refractory. Documented decreases in seizure frequency associated with cannabis use were transient for many patients. There was limited variation in the ratios of CBD to THC. All prospective studies evaluating efficacy for seizure control have used pure CBD preparations or oils with high CBD concentrations. It is unclear whether other compounds contained within cannabis-derived oils could contribute to the documented decrease in seizure frequency observed in this chart review. In the case of patients self-medicating with cannabis, a discussion of risks and benefits should take place between health care professionals and the patients and their families. This study has identified the need for development of a standardized care record, to ensure greater consistency and rigour in the conduct of prospective research in cannabis treatment and thus to generate better-quality research on the therapeutic effects of medical cannabis. We have proposed a template suitable for adoption by other hospitals that allows for a more structured documentation process, thereby facilitating the capture of more robust data on cannabis use in hospital settings. Overall, there continues to be a need for further research and for well-designed clinical trials of the use of cannabis for therapeutic purposes in pediatrics.

\section{References}

1. Alper BS, Manheimer EW, Ehrlich A. Point-of-care application of: 'Trial of cannabidiol for drug-resistant seizures in the Dravet syndrome'. Eur J Integr Med. 2017;14:20-1.

2. Gofshteyn JS, Wilfong A, Devinsky O, Bluvstein J, Charuta J, Ciliberto MA, et al. Cannabidiol as a potential treatment for febrile infection-related epilepsy syndrome (FIRES) in the acute and chronic phases. J Child Neurol. 2017;32(1):35-40.

3. Kaplan EH, Offermann EA, Sievers JW, Comi AM. Cannabidiol treatment for refractory seizures in Sturge-Weber syndrome. Pediatr Neurol. 2017; 71:18-23.e2.

4. Treat L, Chapman KE, Colborn KL, Knupp KG. Duration of use of oral cannabis extract in a cohort of pediatric epilepsy patients. Epilepsia. 2017;58(1):123-7.

5. Devinsky O, Marsh E, Friedman D, Thiele E, Laux L, Sullivan J, et al. Cannabidiol in patients with treatment-resistant epilepsy: an open-label interventional trial. Lancet Neurol. 2016;15(3):270-8.

6. Tzadok M, Uliel-Siboni S, Linder I, Kramer U, Epstein O, Menascu S, et al. CBD-enriched medical cannabis for intractable pediatric epilepsy: the current Israeli experience. Seizure. 2016;35:41-4.

7. Hussain SA, Zhou R, Jacobson C, Weng J, Cheng E, Lay J, et al. Perceived efficacy of cannabidiol-enriched cannabis extracts for treatment of pediatric epilepsy: a potential role for infantile spasms and Lennox-Gastaut syndrome. Epilepsy Behav. 2015;47:138-41.

8. Press CA, Knupp KG, Chapman KE. Parental reporting of response to oral cannabis extracts for treatment of refractory epilepsy. Epilepsy Behav. 2015;45:49-52.

9. Saade D, Joshi C. Pure cannabidiol in the treatment of malignant migrating partial seizures in infancy: a case report. Pediatr Neurol. 2015;52(5):544-7.

10. Porter BE, Jacobson C. Report of a parent survey of cannabidiol-enriched cannabis use in pediatric treatment-resistant epilepsy. Epilepsy Behav. 2013;29(3):574-7. 
11. Hasan A, Rothenberger A, Münchau A, Wobrock T, Falkai P, Roessner V. Oral delta 9-tetrahydrocannabinol improved refractory Gilles de la Tourette syndrome in an adolescent by increasing intracortical inhibition: a case report. J Clin Psychopharmacol. 2010;30(2):190-2.

12. Rudich Z, Stinson J, Jeavons M, Brown SC. Treatment of chronic intractable neuropathic pain with dronabinol: case report of two adolescents. Pain Res Manag. 2003;8(4):221-4.

13. Harrison TE, Bruce BK, Weiss KE, Rummans TA, Bostwick JM. Marijuana and chronic nonmalignant pain in adolescents. Mayo Clin Proc. 2013; 88(7):647-50.

14. Elder JJ, Knoderer HM. Characterization of dronabinol usage in a pediatric oncology population. J Pediatr Pharmacol Ther. 2015;20(6):462-7.

15. Abrahamov A, Abrahamov A, Mechoulam R. An efficient new cannabinoid antiemetic in pediatric oncology. Life Sci. 1995;56(23-24):2097-102.

16. Chan HSL, Correia JA, MacLeod SM. Nabilone versus prochlorperazine for control of cancer chemotherapy-induced emesis in children: a double-blind, crossover trial. Pediatrics. 1987;79(6):946-52.

17. Dalzell AM, Bartlett H, Lilleyman JS. Nabilone: an alternative antiemetic for cancer chemotherapy. Arch Dis Child. 1986;61(5):502-5.

18. Ekert $\mathrm{H}$, Waters KD, Jurk IH, Mobilia J, Loughnan P. Amelioration of cancer chemotherapy-induced nausea and vomiting by delta-9tetrahydrocannabinol. Med J Aust. 1979;2(12):657-9.

19. Kuhlen M, Hoell JI, Gagnon G, Balzer S, Oommen PT, Borkhardt A, et al. Effective treatment of spasticity using dronabinol in pediatric palliative care. Eur J Paediatr Neurol. 2016;20(6):898-903.

20. Wong SS, Wilens TE. Medical cannabinoids in children and adolescents: a systematic review. Pediatrics. 2017;140(5):e20171818.

21. Rieder MJ; Canadian Paediatric Society, Drug Therapy and Hazardous Substances Committee. Is the medical use of cannabis a therapeutic option for children? Paediatr Child Health. 2016;21(1):31-4.

22. Sekar K, Pack A. Epidiolex as adjunct therapy for treatment of refractory epilepsy: a comprehensive review with a focus on adverse effects. F1000Res. 2019;8(F1000 Faculty Rev):234.

23. Verrotti A, Castagnino M, Maccarrone M, Fezza F. Plant-derived and endogenous cannabinoids in epilepsy. Clin Drug Invest. 2016;36(5):331-40.

24. Szaflarski JP, Bebin EM. Cannabis, cannabidiol, and epilepsy-from receptors to clinical response. Epilepsy Behav. 2014;41:277-82.

25. Korantzopoulos P, Liu T, Papaioannides D, Li G, Goudevenos JA. Atrial fibrillation and marijuana smoking. Int J Clin Pract. 2008;62(2):308-13.

26. Singh D, Huntwork M, Shetty V, Sequeira G, Akingbola O. Prolonged atrial fibrillation precipitated by new-onset seizures and marijuana abuse. Pediatrics. 2014;133(2):e443-6.

27. Wolff $\mathrm{V}$, Rouyer $\mathrm{O}$, Geny B. Adverse health effects of marijuana use. $N E n g l$ JMed. 2014;371(9):878.

28. Mallat A, Roberson J, Brock-Utne JG. Preoperative marijuana inhalationan airway concern. Can J Anaesth. 1996;43(7):691-3.

29. Maa E, Figi P. The case for medical marijuana in epilepsy. Epilepsia. 2014;55:783-6.

30. Gilman JM, Kuster JK, Lee S, Lee MJ, Kim BW, Makris N, et al. Cannabis use is quantitatively associated with nucleus accumbens and amygdala abnormalities in young adult recreational users. J Neurosci. 2014; 34(16):5529-38.
31. Tamm L, Epstein JN, Lisdahl KM, Molina B, Tapert S, Hinshaw SP, et al; MTA Neuroimaging Group. Impact of ADHD and cannabis use on executive functioning in young adults. Drug Alcohol Depend. 2013; 133(2):607-14.

32. Understanding the new access to cannabis for medical purposes regulations. Health Canada; 2016 [cited 2017 May 22]. Available from: https:// www.canada.ca/en/health-canada/services/publications/drugs-healthproducts/understanding-new-access-to-cannabis-for-medical-purposesregulations.html

33. McCoy B, Wang L, Zak M, Al-Mehmadi S, Kabir N, Alhadid K, et al. A prospective open-label trial of a CBD/THC cannabis oil in Dravet syndrome. Ann Clin Transl Neurol. 2018;5(9):1077-88.

34. Perucca E, Gram L, Avanzini G, Dulac O. Antiepileptic drugs as a cause of worsening seizures. Epilepsia. 1998;39(1):5-17.

35. Aldenkamp AP, Alpherts WC, Sandstedt P, Blennow G, Elmqvist D, Heijbel $\mathrm{J}$, et al. Antiepileptic drug-related cognitive complaints in seizure-free children with epilepsy before and after drug discontinuation. Epilepsia. 1998; 39(10):1070-4

36. Mckiernan A, Fleming K. Canadian youth perceptions on cannabis. Canadian Centre on Substance Abuse; 2017.

37. Fischer B, Russell C, Sabioni P, Van den Brink W, Le Foll B, Hall W, et al. Lower-risk cannabis use guidelines: a comprehensive update of evidence and recommendations. Am J Public Health 2017;107(8):e1-e12.

38. Grant CN, Bélanger RE; Canadian Paediatric Society, Adolescent Health Committee. Cannabis and Canadảs children and youth [position statement]. Paediatr Child Health. 2017;22(2):98-102.

39. Access to Cannabis for Medical Purposes Regulations, SOR/2016-230.

Régis Vaillancourt, OMM, CD, BPharm, PharmD, FCSHP, is with the Department of Pharmacy, Children's Hospital of Eastern Ontario, Ottawa, Ontario.

Maria Moreno, PharmD, is with the Leslie Dan School of Pharmacy, University of Toronto, Toronto, Ontario.

Annie Pouliot, PhD, was, at the time this study was conducted, with the Department of Pharmacy, Children's Hospital of Eastern Ontario, Ottawa, Ontario.

Erick Sell, MD, is with the Faculty of Medicine, University of Ottawa, Ottawa, Ontario.

Competing interests: None declared.

Address correspondence to:

Dr Régis Vaillancourt

Department of Pharmacy

Children's Hospital of Eastern Ontario

401 Smyth Road

Ottawa ON K1H 8L1

e-mail: rvaillancourt@cheo.on.ca

Funding: None received. 